\title{
Factors Associated With Failure to Complete Phase II Cardiac Rehabilitation: Survey Registry in Rajaie Cardiovascular Medical and Research Center
}

\author{
Bahieh Moradi ${ }^{1}$, Maryam Esmaeilzadeh ${ }^{2^{*}}$, Majid Maleki ${ }^{1}$, Leila Sari ${ }^{1}$ \\ ${ }^{1}$ Department of Prevention and Cardiac Rehabilitation, Rajaie Cardiovascular Medical and Research Center, Tehran University of Medical Sciences, Teh- \\ ran, IR Iran \\ ${ }^{2}$ Echocariography Research Center, Rajaie Cardiovascular Medical and Research Center, Tehran University of Medical Sciences, Tehran, IR Iran
}

\begin{tabular}{|c|c|}
\hline A R T I C L E I N F O & A B S T R A C T \\
\hline $\begin{array}{l}\text { Article type: } \\
\text { Original Articles }\end{array}$ & $\begin{array}{l}\text { Background: A significant proportion of patients who begin CR (cardiac rehabilitation) } \\
\text { do not complete the program. }\end{array}$ \\
\hline Article history: & $\begin{array}{l}\text { Objectives: The purpose of this study was to determine the predicting factors that inter- } \\
\text { fere with adherence and completion of an outpatient CR program. }\end{array}$ \\
\hline Received: 21 Apr 2011 & Patients and Methods: A cross-sectional survey was conducted with all 128 patients who \\
\hline Revised: 30 Apr 2011 & entered the CR program at the Rajaie Cardiovascular Medical and Research Center in \\
\hline Accepted: 5 Jan 2011 & Tehran, IR Iran, from March 2009 to March 2010. The demographic variables included \\
\hline Keywords: & ables were compared in patients who completed and did not complete phase II CR. The \\
\hline Heart & reason for CR incompletion was asked in follow-up phone interviews. \\
\hline Rehabilitation & Results: The most frequent clinical diagnosis among the patients enrolled in the CR pro- \\
\hline Exercise Test & $\begin{array}{l}\text { gram was coronary artery disease. } 83.6 \% \text { of patients who participated had a CABG or PCI } \\
\text { procedure during the last year. CR participation increased when cardiac revasculariza- } \\
\text { tion procedures were performed during the first hospitalization. } 88 \text { of the } 128 \text { patients } \\
\text { dropped out, yielding a dropout rate of } 68.7 \% \text {, which was significantly }(P<0.01) \text { higher } \\
\text { than the same study in other countries. Sex and age did not predict the completion rate. } \\
\text { As education increased, cardiac rehabilitation utilization and completion increased. Un- } \\
\text { employed patients were less likely than employed patients to complete the program. } \\
\text { Conclusions: Our data indicate a low rate of CR completion, with lower rates among } \\
\text { unemploved, uninsured, and less educated patients. }\end{array}$ \\
\hline
\end{tabular}

Copyright $\odot 2011$ Kowsar Corp. All rights reserved.

Implication for health policy/practice/research/medical education:

This article is applicated to all cardiologist, health practitionners, cardiology residents, etc.

- Please cite this paper as:

Moradi B, Esmaeilzadeh M, Maleki M, Sari L. Factors Associated With Failure to Complete Phase II Cardiac Rehabilitation: Survey Registry in Rajaie Cardiovascular Medical and Research Center. Int Cardiovasc Res J.2011; 5(4):139-42. DOI: 10.5812/icrj.4370

\section{Background}

Research in phase II cardiac rehabilitation (CR) consistently shows that patients experience significant in-

\footnotetext{
* Corresponding author: Maryam Esmaeilzadeh, Echocariography Research Center, Rajaie Cardiovascular Medical and Research Center, Tehran University of Medical Sciences, Tehran, IR Iran. Tel: +98-2123922131, Fax: +982122055594,E-mail: meszadeh@rhc.ac.ir

DOI:10.5812/icrj.4370

Copyright $\odot 2011$ Kowsar Corp. All rights reserved.
}

creases in exercise capacity after completing a phase II CR program (1-5). This increase in exercise capacity may be one of the factors contributing to the 20 to $30 \%$ reduction in mortality and significant improvement in quality of life $(1,6)$. Despite these promising findings, however, adherence to such programs remains problematic (79). Previous studies have found dropout rates ranging from 10 to $36 \%(5,7,8)$. Even when patients do not drop out of phase II CR, after completing their program many patients' exercise adherence levels decline even further 
than do the exercise levels of program dropouts (6, 8-10). Research has shown that the greatest health benefits of CR programs are associated with ongoing adherence to CR through 12 weeks of exercise or longer (11). Those Cardiovascular patients who do not engage in CR and those who drop out prior to completion are therefore likely to be at greater risk of experiencing further cardiac events than those who attend all prescribed CR classes (12).

Some studies have investigated the problem of poor CR attendance over the last 2 decades. These studies have consistently found that sociodemographic and medical variables, such as physician recommendation and sex (4, 5), and cognitive factors (i. e. beliefs about their illness, beliefs about CR, and feelings of self-efficacy, mood, and coping style) have a significant impact on referral to CR and ongoing adherence (6).

\section{Objectives}

Because of the variability of these factors in different countries, the present study aimed to evaluate the factors associated with failure to complete an outpatient, phase II CR program in Tehran, IR Iran.

\section{Patients and Methods}

This study was conducted at the Rajaie Cardiovascular Medical and Research Center, the largest cardiovascular center in Iran. All patients entering our rehabilitation program over a period of 12 months (from March 2009 to March 2010) were studied.

Data collection was done by a CR nurse 1 month after the last session of patient participation in the phase II CR program. Sociodemographic data were recorded and included age, sex, marital status, employment status, education level, and return to work (yes or no). Information was also collected on admitting diagnosis and left ventricular ejection fraction (LVEF) at the time of CR attendance. The format was similar to those used in previous studies $(6,13,14)$.

In our center, phase II CR comprises 24 exercise training sessions and patient education. The exercise program consisted of 1-hour aerobic and strength exercise sessions over an 8- to 12-week period. The education component was an 8-week rolling program of 30-minute talks led by cardiologists from multiple disciplines contributing to CR. The talks were titled "How the Heart Works," "Risk Factors," "Drugs and the Heart," "Coping with Worrying Thoughts," "Relaxation," "Exercise and the Heart," "Healthy Eating," and "Food Labeling." Talks were held immediately following exercise classes for patient convenience. The course was repeated continuousely every 8 weeks all year.

All participants who did not complete the CR program were contacted by phone by a CR nurse 2 to 4 weeks after program cessation to ascertain the reasons of program incompletion. The reasons spanned 5 issues: lack of insurance coverage or financial problems, long distance between the CR center and home or workplace, rehos- pitalization or medical reasons, lack of motivation and personal problems (i. e. traveling, sickness of family members).

\subsection{Statistical Analysis}

All data analyses were performed using SPSS, version 19. Means, standard deviations, and medians were calculated for descriptive purposes. Finally, chi squares, Fisher's exact tests, and Mann Whitney U tests were used to analyze the data. $P$ values under .05 were considered significant.

\section{Results}

Within the study period, 128 cardiac patients with a mean age of $55.5 \pm 10.1$ years joined our CR program. Of these participants, 106 (82.8\%) were male. The most common reason (57 patients) for presentation was CABG ( coronary artery bypass graft surgery), followed by PCI (percutaneous coronary intervention ; 50 patients). The remainder (20 patients) had other cardiac diagnoses such as myocardial infarction (MI), valve disease, heart failure, or arrhythmias. The majority of patients (60.1\%) were employed. The most frequent category of employment was defined as "governmental occupation." Demographic characteristics of the patients are summarized in Table 1.

Throughout the study duration, 88 out of the 128 patients dropped out, yielding a completion rate of $31 \%$. The most common reasons of leaving the program were far distance between the patient's home or workplace and CR center (69.6\%), expensive cost or lack of insurance

\begin{tabular}{|c|c|c|}
\hline Demographic Variable & No. & $\%$ \\
\hline \multicolumn{3}{|l|}{ Marital status } \\
\hline Married & 128 & 100 \\
\hline \multicolumn{3}{|l|}{ Education level } \\
\hline Academic & 40 & 31.3 \\
\hline High school & 42 & 32.8 \\
\hline$<$ High school graduation & 37 & 28.9 \\
\hline Uneducated & 9 & 7.03 \\
\hline \multicolumn{3}{|l|}{ Employment status } \\
\hline Employed & 77 & 60.1 \\
\hline Retired/ unemployed & 36 & 28.1 \\
\hline Housekeeper & 15 & 11.7 \\
\hline \multicolumn{3}{|l|}{ Admitting diagnosis } \\
\hline Bypass surgery & 57 & 44.5 \\
\hline Coronary angioplasty & 50 & 39.1 \\
\hline Heart failure & 11 & 8.6 \\
\hline MI a/angina & 4 & 3.1 \\
\hline Valvular disease & 2 & 1.6 \\
\hline Others & 4 & 3.2 \\
\hline \multicolumn{3}{|l|}{ Insurance coverage } \\
\hline Yes & 68 & 53.2 \\
\hline No & 60 & 46.8 \\
\hline
\end{tabular}




\begin{tabular}{|c|c|c|c|}
\hline Characteristics & Patients Who Completed Program & Patients Who Dropped Out & P value \\
\hline Age, y & $54.2 \pm 11.1$ & $56 \pm 9.6$ & 0.220 \\
\hline Male,\% & 79.6 & 84.1 & 0.571 \\
\hline $\operatorname{LVEF}^{\mathrm{a}}, \%$, mean $\pm \mathrm{SD}$ & $45.3 \pm 13$ & $35 \pm 10$ & $0.016^{\mathrm{b}}$ \\
\hline Return to work, \% & 89.8 & 55.5 & $<0.001$ \\
\hline Uneducation, \% & 7.0 & 2.5 & 0.042 \\
\hline Uninsured, \% & 32.5 & 53.3 & $0.036^{\mathrm{b}}$ \\
\hline \multicolumn{4}{|l|}{ Cardiac diagnosis, $\%$} \\
\hline $\mathrm{CABG}^{\mathrm{a}}$ & 45.03 & 44.3 & 0.306 \\
\hline $\mathrm{PCI}^{\mathrm{a}}$ & 25.0 & 45.5 & $0.025^{\mathrm{b}}$ \\
\hline Heart failure & 14.8 & 5.7 & $0.010^{\mathrm{b}}$ \\
\hline $\mathrm{MI}^{\mathrm{a}} /$ angina & 7.5 & 1.1 & 0.06 \\
\hline Valvular diseases & 2.48 & 1.1 & 0.08 \\
\hline Others & 4.92 & 2.3 & 0.06 \\
\hline Unemployment, \% & 25.4 & 29.5 & $0.044^{\mathrm{b}}$ \\
\hline
\end{tabular}

a Abbreviations: CABG, coronary artery bypass surgery; LVEF, left ventricular ejection fraction; PCI, percutaneous coronary intervention; MI, myocardial infarction

b Statistically significant

(21.4\%), and lack of motivation (7.09\%). To further evaluate the representativeness of the findings, those who completed the program were compared with those who dropped out on the same demographic and medical variables (Table 2). The two groups were similar on most of variables, except for education level $(P=.042)$, insurance coverage $(P=.036)$, and $\operatorname{LVEF}(P=.016)$. Specifically, patients who completed the study were more likely to have postsecondary education (71.04\%) compared with those who dropped out (49.8\%). Among patients who completed the program, $67.5 \%$ were insured, but just $46.5 \%$ of patients who dropped out were insured.

The patients with an LVEF level $\leq 30 \%$ had a higher rate of CR program completion than those with an LVEF level $\geq 45 \%$. The rate of return to work was significantly greater for patients who completed the CR program than for those who dropped out $(P=.016)$.

\section{Discussion}

The results of this study show some differences in the framework of CR adherence and completion, compared with previous studies. During the study period, 3,577 revascularization procedures (1,474 CABG and 2,103 PCI) were completed in our center, but only 128 patients participated in the CR program. Unfortunately, we do not have any formal governmental statics about the participation rates of patients in CR programs, but only these data, which were collected from the largest heart center in country, could indicate the low participation of patients in CR programs.

One important finding was the significantly higher dropout rate in this study than in studies from other countries. One possible explanation for this finding could be the low knowledge of physicians and patients about the benefits of CR in IR Iran. In addition to promoting general knowledge about $\mathrm{CR}$, methods to improve referral and participation rates, such as automated systems of referral and home-based cardiac rehabilitation as an alternative to traditional cardiac rehabilitation (15, 16), should be considered more seriously in some countries. Discussion with the patient by a healthcare provider also appears important in improving participation rates (17). Alternative means of service delivery should be considered to broaden access to CR. Psychological interventions aimed at enhancing motivation and adherence should be developed and appropriately evaluated (18).

This study's completion rate of $31 \%$, which is significantly different from the $96 \%$ completion rate reported by Blanchard et al. (6), suggests the existence of some specific contributing factors to CR dropout. The most common reason for the low completion rate was the distance between patients' homes or workplaces and the CR center. This finding indicates that despite the lower age of cardiovascular patients in IR Iran (19), the main reason of the lower supervised CR rate in our country (even in the capital) in comparison with other countries is the limited number of CR centers. Another important finding in the present study was the low completion rate in patients who were unemployed or uninsured. This finding indicates that health providers and insurance companies should pay more attention to these populations.

The limited CR centers, unemployment, and lack of insurance are the main factors that affect CR program completion in our country, so it seems that health providers and insurance companies should pay more attention to these populations. Further research to address these issues in various ways is recommended.

\section{Acknowledgments}

The authors wish to express their gratitude to all personnel in the rehabilitation center and to all patients who participated in this survey. 


\section{Financial Disclosure}

There is no financial disclosure.

\section{Funding/Support}

There is no funding/support.

\section{References}

1. Myers J, Prakash M, Froelicher V, Do D, Partington S, Atwood JE. Exercise capacity and mortality among men referred for exercise testing. N Engl J Med. 2002;346(11):793-801.

2. Oldridge NB, LaSalle D, Jones NL. Exercise rehabilitation of female patients with coronary heart disease. Am Heart J. 1980;100(5):755-7.

3. Ades PA, Waldmann ML, Polk DM, Coflesky JT. Referral patterns and exercise response in the rehabilitation of female coronary patients aged greater than or equal to 62 years. Am J Cardiol. 1992;69(17):1422-5.

4. Lavie CJ, Milani RV. Effects of cardiac rehabilitation and exercise training on exercise capacity, coronary risk factors, behavioral characteristics, and quality of life in women. Am J Cardiol. 1995;75(5):340-3.

5. Balady GJ, Jette D, Scheer J, Downing J. Changes in exercise capac ity following cardiac rehabilitation in patients stratified according to age and gender. Results of the Massachusetts Association of Cardiovascular and Pulmonary Rehabilitation Multicenter Database. J Cardiopulm Rehabil.1996;16(1):38-46.

6. Blanchard CM, Courneya KS, Rodgers WM, Fraser SN, Murray TC Daub B, et al. Is the theory of planned behavior a useful framework for understanding exercise adherence during phase II cardiac rehabilitation? J Cardiopulm Rehabil. 2003;23(1):29-39.

7. Schuster PM, Waldron J. Gender differences in cardiac rehabilitation patients. Rehabil Nurs. 1991;16(5):248-53.

8. Oldridge NB, Rogowski BL. Self-efficacy and in-patient cardiac rehabilitation. Am J Cardiol. 1990;66(3):362-5.

9. Morrin L, Black S, Reid R. Impact of duration in a cardiac rehabilitation program on coronary risk profile and health-related quality of life outcomes. J Cardiopulm Rehabil. 2000;20(2):115-21.

10. Halm M, Penque S, Doll N, Beahrs M. Women and cardiac rehabilitation: referral and compliance patterns. J Cardiovasc Nurs. 1999;13(3):83-92.

11. Oldridge NB, Guyatt GH, Fischer ME, Rimm AA. Cardiac rehabilitation after myocardial infarction. Combined experience of randomized clinical trials. JAMA. 1988;260(7):945-50.

12. Taylor GH, Wilson SL, Sharp J. Medical, psychological, and sociodemographic factors associated with adherence to cardiac rehabilitation programs: a systematic review. J Cardiovasc Nurs. 2011;26(3):202-9.

13. Blanchard CM, Rodgers WM, Courneya KS, Daub B, Black B. Selfefficacy and mood in cardiac rehabilitation: should gender be considered? Behav Med. 2002;27(4):149-60.

14. Blanchard C, Courneya K, Rodgers W, Daub B, Knapik G. Determinants of exercise intention and behavior during and following phase II cardiac rehabilitation: An application of the theory of planned behavior. Rehabil Psychol. 2002;47(3):308-23.

15. Grace SL, Grewal K, Stewart DE. Factors affecting cardiac rehabilitation referral by physician specialty. I Cardiopulm Rehabil Prev. 2008;28(4):248-52.

16. Reeves GR, Whellan DJ. Recent advances in cardiac rehabilitation. Curr Opin Cardiol. 2010;25(6):589-96.

17. Dunlay SM, Witt BJ, Allison TG, Hayes SN, Weston SA, Koepsell E, et al. Barriers to participation in cardiac rehabilitation. Am Heart J. 2009;158(5):852-9.

18. Sharp J, Freeman C. Patterns and predictors of uptake and ad herence to cardiac rehabilitation. J Cardiopulm Rehabil Prev. 2009;29(4):241-7.

19. Evans J, Bethell H, Turner S, Yadegarfar G. Characteristics of patients entering cardiac rehabilitation in the United Kingdom 1993-2006: implications for the future. J Cardiopulm Rehabil Prev. 2011;31(3):181-7. 